\title{
cAMP and cell sorting control the spatial expression of a developmentally essential cell-type-specific ras gene in Dictyostelium
}

\author{
R. Keith Esch and Richard A. Firtel \\ Department of Biology, Center for Molecular Genetics, University of California-San Diego, La Jolla, California 92093 USA
}

The Dictyostelium ras gene (Dd-ras) is expressed at a low level in vegetative cells, is not expressed between the onset of development and aggregation, and is then re-expressed in the multicellular aggregate stages from the distal, now cAMP-responsive, promoter and from two more proximal promoters. Expression of activated Dd-ras $\left(G_{12} \rightarrow T_{12}\right)$ (Reymond et al. 1986) results in an abnormal developmental phenotype with the formation of aggregates having multiple tips and an inhibition of further development. In this report we investigate the spatial expression of $D d$-ras by fusing the 5 -flanking region to the Escherichia coli lacZ gene and by staining aggregates for $\beta$-galactosidase ( $\beta$-gal) activity. We show that fusions using 5 -flanking sequences that include all promoters are expressed in $\sim 10-20 \%$ of the cells randomly scattered within the early aggregate. Our data indicate that these $\beta$-gal-expressing cells migrate to newly formed tips of aggregates and localize in the region that becomes the prestalk zone. Staining is also seen in the very posterior of the organism. The anterior staining appears to be specific for the prestalk $A$ population, and $\beta$-gal activity is subsequently present in stalk cells as developmental proceeds. When only the two more proximal promoters are used to drive lac $Z$ expression, localized staining is seen in the anterior prestalk region, although it is weaker than with the construct carrying all promoters. Moreover, staining is not seen in the posterior domain in the first finger stage, suggesting differences in the spatial expression from the different promoters. Staining is also observed in some cells within the prespore region, which could be anterior-like cells. The pattern of $D d$-ras/lacZ staining during tip formation suggests a directed, spiral pattern of cell migration, possibly in response to the proposed spiral gradient of cAMP within the developing aggregate. The pattern of Dd-ras is consistent with the abnormal developmental phenotype caused by expressing an activated Dd-ras $\mathrm{Thr}_{12}$ gene and suggests an essential role for Dd-ras in controlling spatial differentiation.

[Key Words: cAMP; Dictyostelium; ras spatial expression; cell sorting]

Received July 25, 1990; revised version accepted October 29, 1990.

Morphological differentiation in Dictyostelium discoideum is initiated upon starvation, when $\sim 10^{5}$ cells aggregate to form a multicellular organism. These cells aggregate in response to extracellular pulsatile signals of cAMP acting via cell-surface cAMP responses. Intracellular and membrane responses to these signals include the activation of adenylate cyclase and secretion of cAMP, the activation of directed chemotaxis toward a higher concentration of cAMP, and the induction of genes whose expression is required for aggregation and later development. The initial spatial patterns of two functionally distinct cell types (prestalk and prespore) can be distinguished when the aggregate forms a tip at $\sim 12 \mathrm{hr}$ of development. By $16 \mathrm{hr}$, a slug or pseudoplasmodium is formed in which the anterior $\sim 15 \%$ of the slug is composed of prestalk cells and the posterior $85 \%$ is composed of predominantly prespore cells. Under appropriate conditions, the migrating slug culminates with the formation of a mature fruiting body containing $\sim 80 \%$ spore cells and $\sim 20 \%$ vacuolated dead stalk cells rising from a basal disk (Loomis 1982; Devreotes 1989; Firtel et al. 1989).

Several classes of genes induced during the multicellular stage by two putative morphogens, cAMP and differentiation-inducing factor (DIF), have been identified by molecular analysis. cAMP acts as an inductive signal for specific prestalk and prespore genes whose expression is preferentially localized to the anterior or the posterior of the migrating slug, respectively (Barklis and Lodish 1983; Mehdy et al. 1983; Krefft et al. 1984; Reymond et al. 1984; Williams et al. 1985, 1989; Datta et al. 1986; Gomer et al. 1986; Jermyn et al. 1987; Haberstroh and Firtel 1990). At approximately the same time in development, DIF induces the expression of two prestalk genes, $D d 56$ and $D d 63$. Localization studies have shown that Dd63 is expressed in prestalk A cells, which com- 
pose most of the prestalk zone, whereas Dd56 is expressed in prestalk B cells, which compose a small coneshaped region in the interior of the prestalk zone (Jermyn et al. 1989; Williams et al. 1989).

Dictyostelium has two ras genes, $D d$-ras and $D d$-ras $G$ (Reymond et al. 1984; Pawson et al. 1985). Dd-rasG is expressed only during vegetative growth (Robbins et al. 1989|. Dd-ras has a more complex pattern of expression, with $1.2-\mathrm{kb}$ mRNA expressed at a low level during growth, repressed during early development, and reinduced in aggregation synchronously with two $\sim 1.0-\mathrm{kb}$ mRNAs. All three late transcripts are inducible in single-cell culture by CAMP, although the two smaller transcripts are induced to a lesser degree (Reymond et al. 1984; R.K. Esch, R.A. Firtel, and P. Howard, unpubl.). Previously, we have suggested-on the basis of experiments using RNA from purified prestalk and prespore cells - that $D d$-ras is preferentially expressed in prestalk cells in the multicellular stages, although this claim has been disputed (Jermyn et al. 1987).

The expression of an activated Dd-ras protein $\left(\mathrm{Gly}_{12} \rightarrow \mathrm{Thr}_{12}\right)$ results in an altered pattern of morphological differentiation (Reymond et al. 1986). The cells do not aggregate in submerged culture. On an air-buffer interface, cells aggregate into mounds with multiple tips; but, in most cases, development does not proceed any further, indicating that ras plays a critical role in some process regulating development. Expression of the activated ras protein has no effect on CAMP receptor activation of adenylate cyclase (Reymond et al. 1986), but it does result in a more rapid adaptation in the cAMP activation of guanylate cyclase, thus implicating a $D d$ ras function in the cAMP-mediated signal transduction pathway controlling chemotaxis /van Haastert et al. 1987). Antisense mutagenesis approaches suggest that ras is also essential for cell growth (Reymond et al. 19851.

Since $D d$-ras is implicated as an important component in the cAMP-mediated signal transduction pathways, we chose to examine the spatial expression of this gene to understand better the role of Dd-ras in multicellular development. Moreover, we were interested in the ontogeny of prestalk cells that express a cAMP-induced gene and in examining possible roles of such cells in establishing spatial patterning within the multicellular aggregate. In this report we use $D d$-ras/lac $Z$ gene fusions to investigate the spatial distribution of expression of this gene. We show that during multicellular development, $D d$-ras expression is prestalk specific and appears to be localized to the prestalk A cell population and basal cells (i.e., cells at the base of the standing slug and in the basal disk of the fruiting body). By examining the ontogeny of the Dd-ras-expressing cells, we show that the initial patterning is not spatially organized. Rather, we suggest that the prestalk-specific pattern is produced by directed cell sorting, possibly in response to cAMP signals. Our analysis provides additional insights into prestalk and stalk cell differentiation and suggests that cAMP-induced prestalk-specific genes, such as Dd-ras, as well as DIF-inducible genes, may establish the initial patterning. The relationship between cells expressing the DIF-inducible prestalk gene Dd63 and the cAMP-inducible ras gene is discussed.

\section{Results \\ Dd-ras expression is spatially regulated and cell-type specific}

We have shown previously that $680 \mathrm{bp}$ of $5^{\prime}$-flanking region of the Dictyostelium Dd-ras gene (see Fig. 1A) confers proper developmental and cAMP-inducible expression with RNAs that have the same start site as the endogenous transcripts when the region is fused to various reporter genes (Reymond et al. 1985, 1986; R.K. Esch, R.A. Firtel, and P. Howard, unpubl.; see also below). These data are summarized in Figure 1B.

To examine the spatial expression of $D d$-ras, we fused this 5 '-flanking region to the $E$. coli lacZ gene encoding $\beta$-galactosidase ( $\beta$-gal) and used it to transform Dictyostelium (see Materials and methods). When migrating slugs expressing the $D d$-ras/lacZ gene fusion are stained for $\beta$-gal activity, specific staining is observed in the anterior, prestalk region of the slug, indicating that at this time of development, $D d$-ras-expressing cells are highly localized and that $D d$-ras expression is specific to prestalk cells (Fig. 2, plate 1E). Multicellular structures formed from untransformed cells show no staining and thus confirm that the observed staining in $D d$-ras/lacZ transformants is due to expression of the $D d$-ras-driven B-gal (Fig. 2, plate 2G).

To understand the origins of this pattern and to examine the fate of these cells during later development, we investigated the spatial distribution of $D d$-ras/lacZexpressing cells from early aggregation through culmination. At the time of midaggregation (Fig. 2, plate 1A), we see a speckled pattern of $\beta$-gal staining throughout the aggregate in which a subset of cells, with no apparent spatial localization, detectably express $\beta$-gal. Staining is seen both within cells of the central region, which will predominantly become prespore, as well as in the skirt of cells still moving into the forming aggregate. In contrast, none of the cells within this skirt stain with a lacZ fusion expressed from a cAMP-inducible prespore promoter (SP60), although eventually many of these will differentiate into prespore cells (Haberstroh and Firtel 1990). As the aggregate begins to form a tip, localization of $D d$-ras-directed $\beta$-gal staining cells at the tip is observed [Fig. 2, plate 1A (aggregate with arrow), plate $1 \mathrm{C}$; see below]. At the time of the finger stage, stained cells are almost exclusively present at the anterior tip and in basal cells at the bottom of the finger; in addition, occasional $\beta$-gal-expressing cells are seen throughout the aggregate. The finger then falls over and forms a migrating slug (Fig. 2, plate 1E). When the slug migrates, many of the basal cells are sloughed off as a group (see arrow, Fig. 2 , plate $2 \mathrm{~A}$ ). After a period of migration ranging from $<1$ $\mathrm{hr}$ to $>24 \mathrm{hr}$, one sees some slugs in which the anterior region and a few cells in the posterior region stain. In other slugs, we observe a small, stained posterior region 

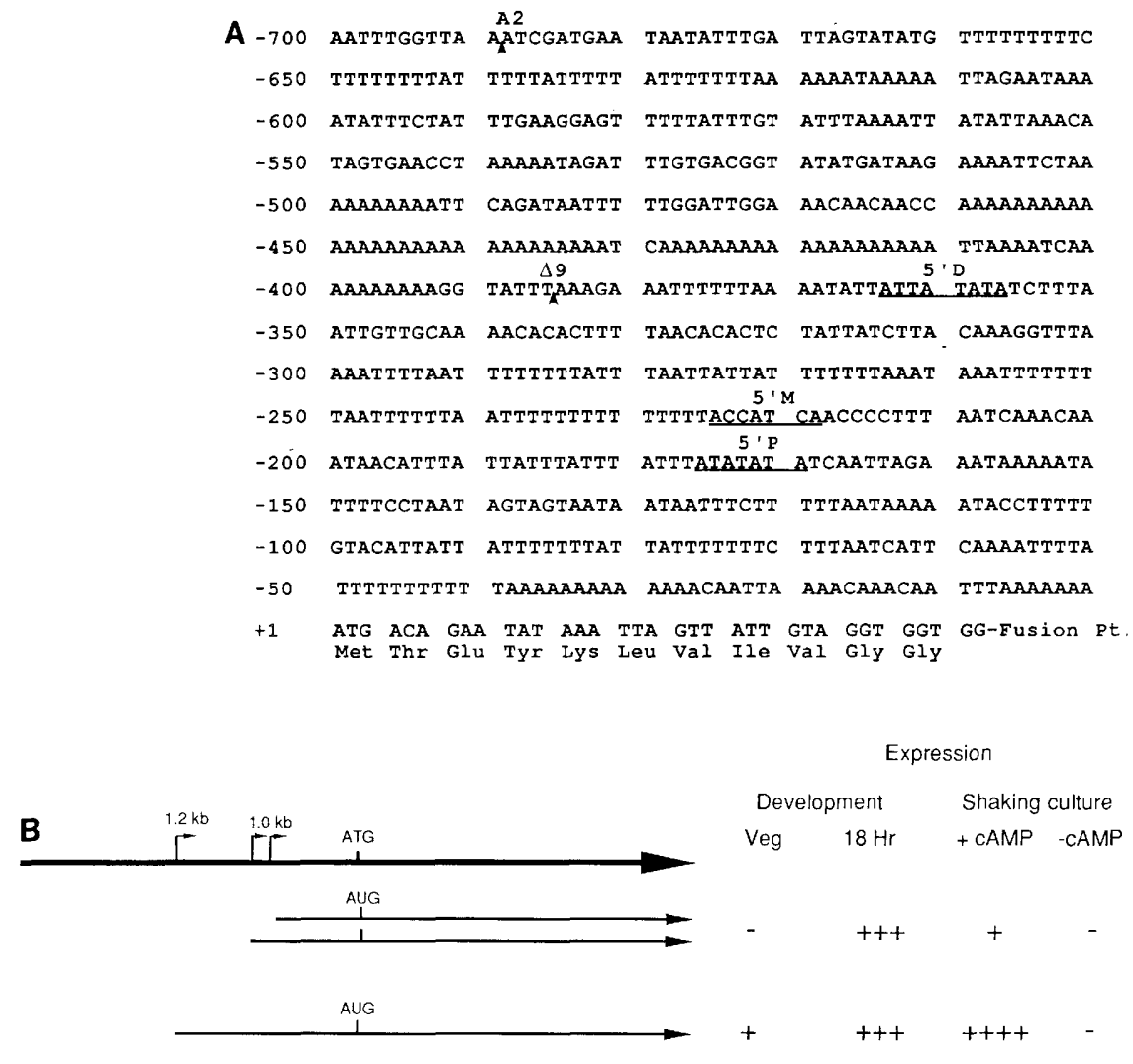

followed by a trail of small mounds of $\beta$-gal-staining cells. These results suggest that the basal cells are lost periodically and that cells now found in the posterior region are induced to express $D d$-ras/lacZ. However, we cannot exclude that the new posterior $D d$-rax/lacZ-expressing cells are derived from other $D d$-ras-expressing cells that migrate to the posterior zone. At the late finger stage, just prior to the start of culmination, posterior basal cells express $\beta$-gal activity, again suggesting that these cells continue to redifferentiate and may be essential for fruiting body formation (Fig. 2, plates 1F and 1G).

During culmination, stalk cells differentiate within the anterior region and start to form a stalk tube that ingresses as a column into the center of the prespore zone (Schaap 1986). As can be seen, these forming stalk cells have $D d$-ras promoter-directed $\beta$-gal activity (Fig. 2 , plate $2 \mathrm{D} \mid$. The prespore region rounds up to form a
- galatosidase Expression

Veg

$+++$
$+$
Figure 1. Dd-ras $5^{\prime}$-flanking sequences and constructs. (A) DNA sequence of the $D d$-ras 5 '-flanking region and amino-terminal amino acid sequence up to the reporter gene fusion point. Because of the presence of three promoters, the ATG translation initiation codon is labeled +1 . The underlined bases denote the three transcription start sites, which are labeled 5'D, 5' $\mathrm{M}$, and 5'P for distal, middle, and proximal promoter sites. A2 designates the $5^{\prime}$ position of the "full-length" combined promoter expressing all three transcripts. $\Delta 9$ represents the $5^{\prime}$ position of the construct expressing only the middle and proximal promoters. The 18-hr time point is equivalent to early culminants. (B) The relative sizes and relative developmental expression of $D d$-ras endogenous transcripts and the $D d$-ras/lacZ fusions are shown. + cAMP and - cAMP refer to culture conditions in which single cells are suspended in shaking culture in the presence or absence of $300 \mu \mathrm{M}$ cAMP. Endogenous $D d$-ras or $D d$-ras/reporter gene fusions are assayed after $12 \mathrm{hr}$ (for details of the experiments, see Mehdy et al. 1983; Reymond et al. 1984; Mehdy and Firtel 1985). (18 hr) Time after starvation of cells. The cells at this time in development on filter pads correspond to late second finger/early culminant. The data on the relative level of expression, cAMP responsiveness, and expression in vegetative cells are from this report, Reymond et al. $(1984,1985)$, and unpublished observations (R.K. Esch, R.A. Firtel, and Howard). The structure of the lacZ expression vector used in these studies is given in Haberstroh and Firtel (1990). 
mental pattern of $D d$-ras/lacZ expression is pictorially summarized in Figure 3.

A detailed examination of $D d$-ras/lacZ-expressing cells in the slug and early culminant stages suggests that the pattern is similar to the prestalk A population defined by the localized expression of the DIF-inducible
1
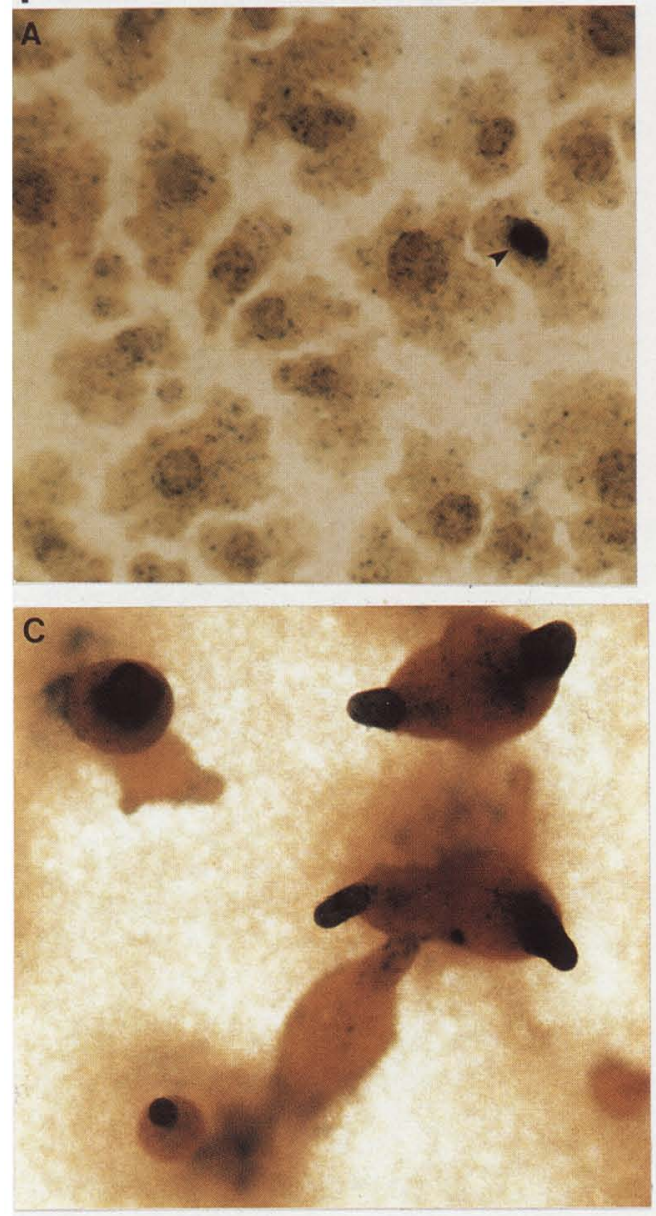

E
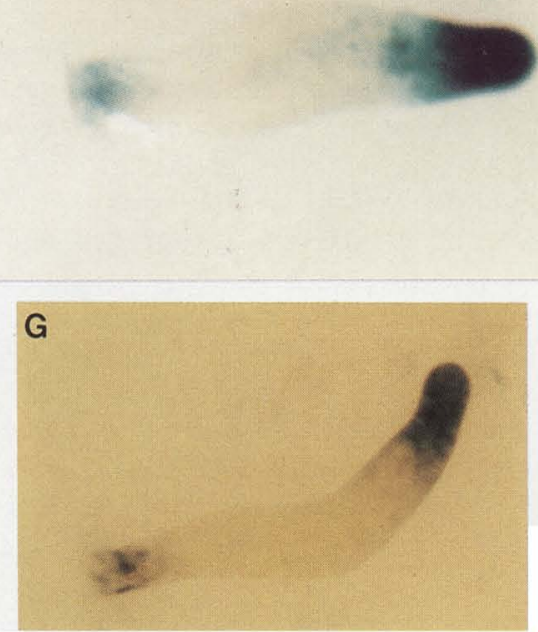
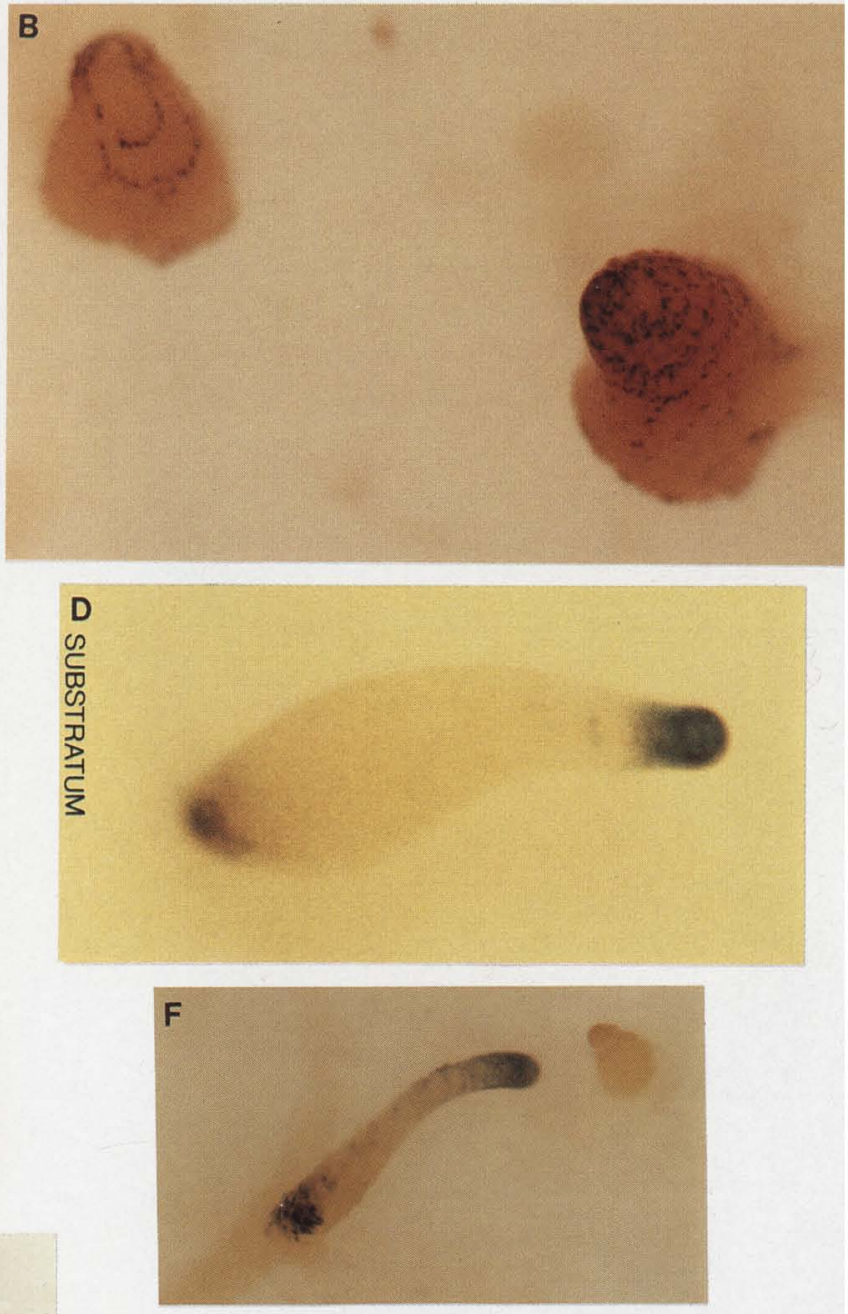

H

Figure 2. Plate 1. (See facing page for legend.) 
gene $D d 63$. As can be seen in Figure 2, plate $1 \mathrm{H}$, there appears to be a cone-shaped nonstaining or more lightly staining region within the anterior of the prestalk zone surrounded by a layer of more intensely staining cells. This apparently nonstaining region closely resembles the prestalk B domain of Dd56-expressing cells.

\section{Expression during growth and preaggregation}

$D d$-ras is also expressed at a low level during vegetative growth. When growing cells are stained, we find that $\sim 8-10 \%$ of the total cell population detectably expresses $\beta$-gal as determined by histochemical staining (Fig. 4E,F; see also Materials and methods). Many of these cells stain very lightly, whereas a few stain more intensely. All, however, require longer staining times $(\sim 30$-fold) to produce visually detectable staining than do cells from multicellular aggregates. This difference in level of expression between vegetative and developing cells is also shown by comparing staining of vegetative

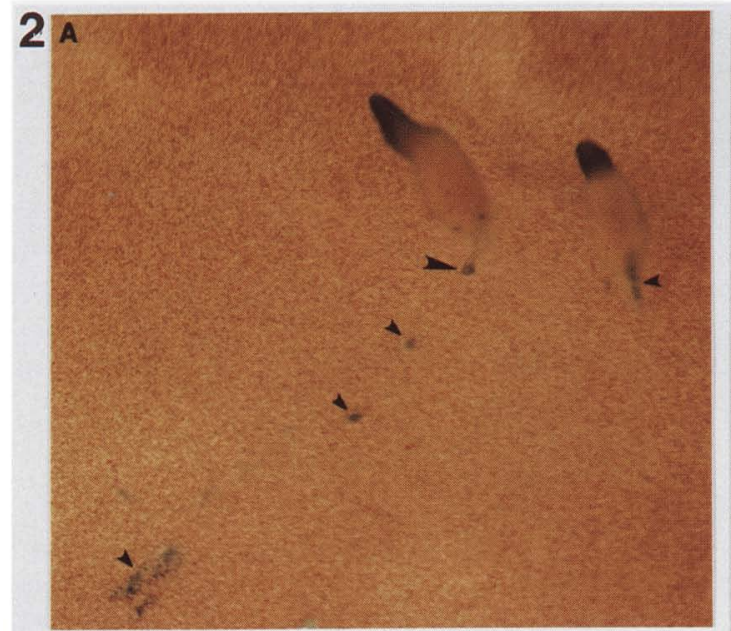

B

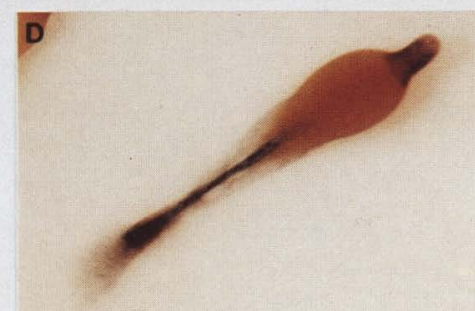

$\mathbf{E}$
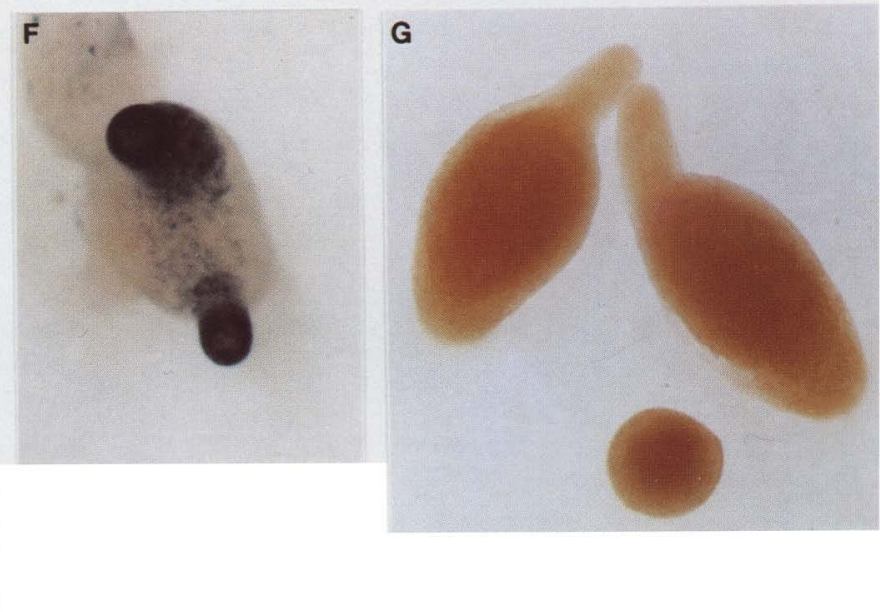

Figure 2. Plate 2. Cytological staining of developing $D d$-ras/lacZ transformants. X-gal is the substrate. Photographs were taken with a compound microscope. Plate 1. (A) Forming aggregates; two show an already formed tip (see arrowheads). (B) Formation of tipped aggregates; note spiral pattern of cells. $(C)$ Early first finger. $(D)$ First finger, side view; (substratum) position of agar surface. $(F)$ First finger. $(E, G, H)$ Slug stage (note lighter cone-shaped region in center of stained domain). Plate 2. $(A-D) D d$-ras/lac $Z$ transformants. $(A)$ Slug migration. Arrowheads show $\beta$-gal-expressing groups of cells lost during migration of one of the slugs; note redifferentiating $D d$-ras-expressing posterior region (larger arrowhead). The other slug has started to culminate. The forming stalk in the posterior (arrowhead) can be seen. (B) Fruiting body (arrowhead indicates $D d$-ras-driven $\beta$-gal expression at the base of the spore mass in a band. $(C)$ Late culminant. $(D)$ Early culminant. $(E, F) \Delta 9 D d$-ras/lacZ transformants at early first finger. $(G)$ Staining of untransformed aggregates. 


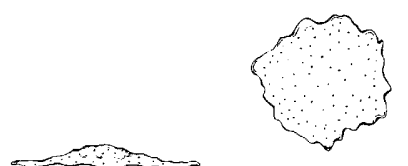

Late Aggregation

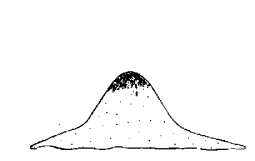

Tipped Aggregate
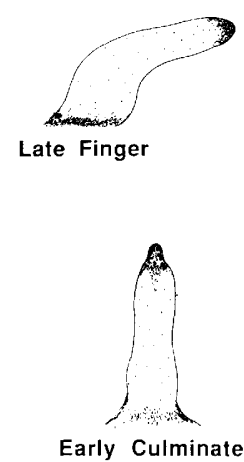

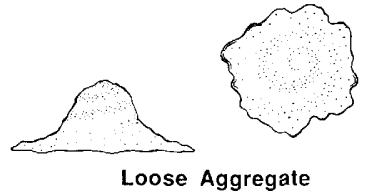

Loose Aggregate
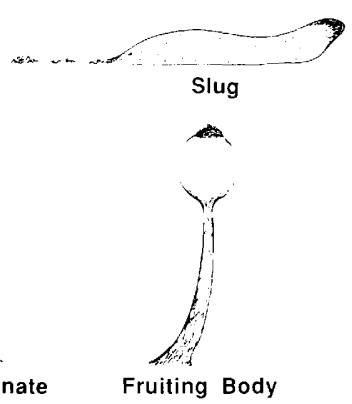

Figure 3. Cartoon of the spatial patterning of Dd-ras expression. Drawings were made from the results of $\beta$-gal expression studies shown in Fig. 2 and others not shown. For the late aggregation and loose aggregate stages, side (left) and top (right) views are shown. The dots representing scatter $\beta$-gal-expressing cells within the middle of the prespore zone of tipped aggregate, early finger, slug, and early culminant stages presumably represent anterior-like cells (Devine and Loomis 1985).

cells to that of dissociated aggregates and slugs as well as comparing assayed $\beta$-gal activities (Fig. 4; Table 1). Since we were concerned that this difference may be due to a molecular heterogeneity in the population of stable transformants, we cloned the Dd-ras/lacZ-expressing cells and examined 11 separate clonal isolates. All showed a staining pattern similar to the original population. This indicates that the $\beta$-gal staining pattern may be determined by cell-to-cell differences and is not due to the presence of clones within the population that have different levels of expression.

Since $D d$-lac $Z$ expression is limited to a similar percentage of cells during vegetative growth $(8-10 \%)$ and aggregation $(15 \%)$, it was important to examine any relationship between staining at these two stages. Previous results show that $D d$-ras mRNA is rapidly lost upon starvation and is then reinduced later during aggregation (Reymond et al. 1984). When vegetatively growing $D$ d-ras/lacZ-transformed cells were washed free of nutrients, shaken for 6-12 hr in buffered salts in the absence of cell-cell contact (fast-shake culture), and then stained, no blue cells were observed and very little activity was detected in $\beta$-gal assays (Table 1 ; see Fig. $4 \mathrm{I})$. Therefore, it is possible that following the fast-shake treatment, many cells express $D d$-ras/lac $Z$ very weakly, but expression of sufficient strength to produce visibly detectable staining in $8-10 \%$ of the cells is lost. When these cells were then plated for development, they did so normally, except the time from plating until aggregation initiated was slightly shorter. When the multicellular aggregates were stained for $\beta$-gal activity, the patterns of all stages were indistinguishable from those seen when vegetative cells were plated immediately (data not shown). $\beta$-Gal assays confirm the loss of activity during fast-shake treatment without cAMP (Table 1). When cells were shaken in the presence of cAMP, a substantial induction of $\beta$-gal activity was seen (Table 1 ), and the cells stained to an intensity similar to that in cells plated for development.

We also note that when cells were stained for $\beta$-gal activity prior to aggregation at $4 \mathrm{hr}$ after starvation, no staining was observed (data not shown). At the very onset of aggregate formation (6-7 hr after starvation), a small fraction of cells scattered through the aggregate stained, but only after several hours of incubation (normal incubation times for $\beta$-gal staining is $20-30$ min). These results indicate that the $\beta$-gal present in some cells during growth is not the same $\beta$-gal present in aggregates and suggest that the activity present in aggregates accumulates from mRNA induced at this time in development, presumably in response to cAMP (Reymond et al. 1984, 1985; R.K. Esch and R.A. Firtel, unpubl.). We cannot determine whether the cells that were expressing $D d$-rax/lac $Z$ during vegetative growth are the same ones that induce the fusion gene later in development within the multicellular aggregate (see Discussion). Experiments examining cells from clonal isolates (see above) indicate that the observed pattern is not due to differences among primary transformants.

\section{Expression from separate promoters}

Using a different $D d$-ras gene fusion $[D d$-ras/E. coli $\beta$ glucuronidase $(\beta$-gluc $)$ minigene $]$, we have initiated a separate set of experiments to map cis-acting regulatory regions controlling $D d$-ras expression (R.K. Esch et al., unpubl.). RNA blots were performed using RNA isolated from stable transformants carrying a complete $D d$-ras regulatory region fused to the $\beta$-gluc minigene (see $\mathrm{Ma}$ terials and methods). Vegetatively growing cells contain a single transcript expressed at a moderately low level that maps to the distal promoter (Fig. 5C). Single-cell, cAMP-induced cultures (data not shown) and developing cells show two bands on RNA blots, as we have shown previously for both endogenous $D d$-ras gene and another reporter gene construct (see Reymond et al. 1984, 1985). The upper of these two bands runs at the same position as the band seen in vegetative cells. S1 nuclease mapping of RNA from 18-hr cells shows three major transcripts (initiating from the $1.2 \mathrm{-kb}$ distal promoter, and the $\sim 1.0$-kb middle and proximal promoters), which initiate at the same position as the endogenous transcripts, as well as some minor bands (R.K. Esch and R.A. Firtel, in prep.; see below). RNA from vegetative cells shows a weak band of the same size as the D promoter transcript 


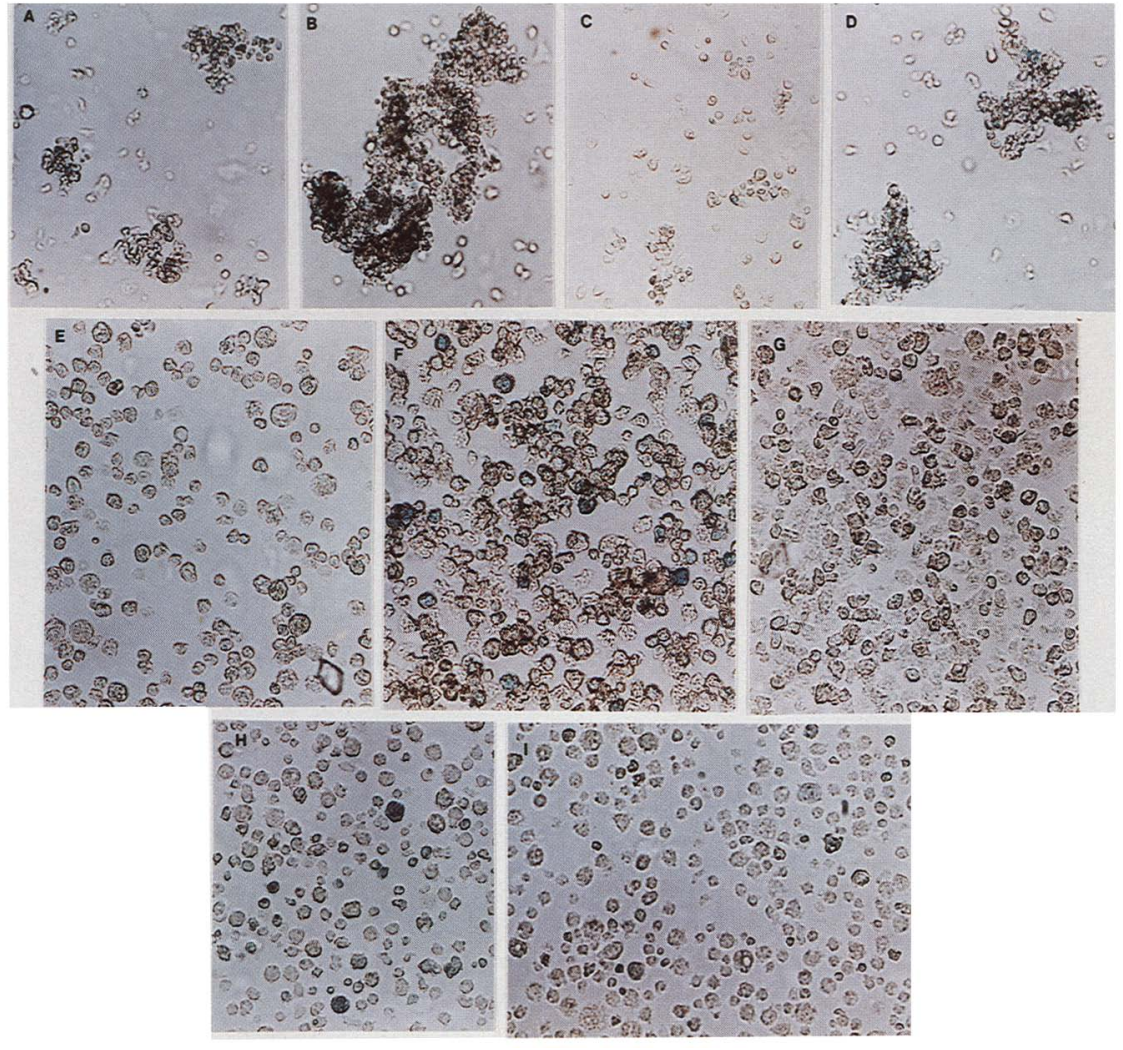

Figure 4. Cytological staining of vegetative cells and cells from dissociated aggregates. Staining for $\beta$-gal expression was done as described in the legend to Fig. 2 and Materials and methods. $(A-D)$ Shown are 16-hr (early slugs) dissociated aggregates. (A) $D d$-ras/lacZ transformants stained for $1 \mathrm{hr}$. $(B) D d$-ras/lacZ stained for $5 \mathrm{hr}$. (C) $5^{\prime} \Delta 9 / 1 a c Z$ stained for $1 \mathrm{hr}$. (D) $5^{\prime} \Delta 9 / l a c Z$ stained for $5 \mathrm{hr}$. $(E-G)$ Vegetative cells. $(E) D d$-ras/lacZ transformants stained for $5 \mathrm{hr}$. $\langle F\rangle D d$-ras $/$ lac $Z$ stained for $15 \mathrm{hr}$. $(G) 5^{\prime} \Delta 9$ stained for $15 \mathrm{hr}$. ( $H$ and I) $\mathrm{Dd}$-ras/lacZ cells from fast-shaking culture with and without exogenous CAMP (see Materials and methods). (H) Dd-ras/ lacZ plus cAMP stained for $15 \mathrm{hr}$. (I) $\mathrm{Dd}$ ras/lac $Z$ minus cAMP stained for $15 \mathrm{hr}$. from $18 \mathrm{hr}$ and an even weaker second band running with the 18-hr M promoter transcript. The low level of D transcript corresponds to that seen on RNA blots; however, no $\mathrm{M}$-sized transcript is seen on RNA blots (see below). In contrast to other reports (Pawson et al.
1985; Robbins et al. 1989), these data, as well as expression of other gene fusions (Reymond et al. 1985; experiments described abovel, indicate that $D d$-ras is expressed in growing cells, albeit at a very low level.

To examine separately expression from the middle

Table 1. $\beta$-Gal assays for Dd-ras/lac $Z$ and $5^{\prime} \Delta 9 /$ lac $Z$ transformants

\begin{tabular}{|c|c|c|c|c|c|c|}
\hline \multirow[b]{2}{*}{ Strain } & \multicolumn{3}{|c|}{$\mathrm{A}^{\mathrm{a}}$} & \multicolumn{3}{|c|}{$\mathrm{B}^{\mathrm{b}}$} \\
\hline & cells & $\begin{array}{c}\beta \text {-gal } \\
\text { activity }\end{array}$ & $\begin{array}{c}\text { (percent of full } \\
\text { expression) }\end{array}$ & cells & cAMP & $\begin{array}{c}\beta \text {-gal } \\
\text { activityc }\end{array}$ \\
\hline \multirow{6}{*}{ Dd-ras/lacZ } & $\mathrm{V}$ & 7.9 & $(10.1)$ & $0 \mathrm{hr}$ & + & 32.8 \\
\hline & & & & & - & 3.6 \\
\hline & $12 \mathrm{hr}$ & 32.4 & (41.3) & $12 \mathrm{hr}$ & + & 52.8 \\
\hline & & & & & - & 48.2 \\
\hline & $17 \mathrm{hr}$ & 78.5 & $(100.0)$ & $17 \mathrm{hr}$ & + & 72.8 \\
\hline & & & & & - & 71.5 \\
\hline \multirow{6}{*}{$5^{\prime} \Delta 9 / 1 a c Z$} & V & 1.0 & $(1.3)$ & $0 \mathrm{hr}$ & + & 1.4 \\
\hline & & & & & - & 0 \\
\hline & $12 \mathrm{hr}$ & 4.8 & (6.2) & $12 \mathrm{hr}$ & + & 3.9 \\
\hline & & & & & - & 4.1 \\
\hline & $17 \mathrm{hr}$ & 29.6 & $(37.7)$ & $17 \mathrm{hr}$ & + & 21.8 \\
\hline & & & & & - & 23.8 \\
\hline
\end{tabular}

aMeasured activities for vegetatively growing cells (V), cells developed to first finger stage (12 hr), and cells developed to slug stage (17 $\mathrm{hr}$ ). Activities are also presented as the percentage of full expression (Dd-ras/lacZ $17 \mathrm{hr}$ ). Values listed have had endogenous $\beta$-gal activity of untransformed Dictyostelium cells (V, 1.6; $12 \mathrm{hr}, 2.1 ; 17 \mathrm{hr}, 2.2)$ subtracted.

${ }^{b}$ Measured activities for cells subjected to fast-shake conditions in the presence $(+)$ and absence $(-)$ of cAMP and then allowed to develop to the stages indicated. $0 \mathrm{hr}$ indicates cells taken from fast-shaking culture prior to plating.

${ }^{\mathrm{c}} \mathrm{pmoles} / \mathrm{min} \cdot \mu \mathrm{g}$ protein. 


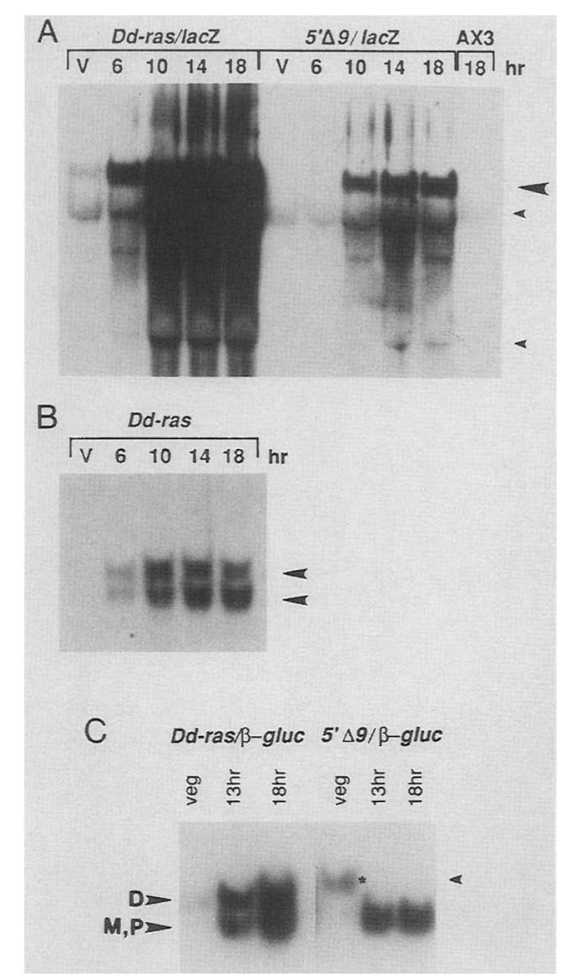

Figure 5. RNA blots of $D d$-ras fusion gene expression. RNA in $A$ was isolated from $D$ d-ras/lacZ and $5^{\prime} \Delta 9 /$ lac $Z$ transformants during vegetative growth (V) and at $6 \mathrm{hr}$ (early aggregate), $10 \mathrm{hr}$ (tipped aggregate), $14 \mathrm{hr}$ (early slug), and $18 \mathrm{hr}$ (early culminant) and hybridized with a lacZ probe. Lane AX3 is RNA from untransformed cells. Note that some RNA smearing is observed. As can be seen with the blot of the same RNA samples probed with $D d$-ras $(B)$, this is due not to degradation but to early termination of expression from long, relatively GC-rich $E$. coli genes in Dictyostelium as we have reported earlier (Datta et al. 1986; Datta and Firtel 1987). Large arrowheads indicate major, full-length products. Small arrowheads in $A$ indicate the positions of the rRNA bands, which cause a compression of smaller, not full-length $D d$-ras/lacZ transcription products. RNA in $C$ was isolated from $D d$-ras/ $\beta$-gluc transformants during growth (veg) and at 13 (first finger) and 18 (early culminant) hr into development and probed with $\beta$-gluc. The large arrowheads indicate the position of specific $D d$-ras/ $\beta$-gluc transcripts. The asterisk and small arrowhead in $C$ (lane $5^{\prime} \Delta 9$, veg) denote a band resulting from transcription initiation within the bacterial vector as determined by S1 nuclease analysis (R.K. Esch et al., in prep.). A corresponding band is absent in the $5^{\prime} \Delta 9 / 1 a c Z$ blot, and no such transcript is detected by $S 1$ nuclease analysis / see Fig. 6). Because of the length of the RNAs, the three transcripts from the $D d$-ras/lacZ gene are not distinguishable by size but can be distinguished by S1 nuclease analysis (see Fig. 6). The probe for the $E$. coli $\beta$-gluc gene was isolated as described previously (Datta and Firtel 1987). Fragments to make both probes were gel-purified and labeled by the random primer method.

and proximal promoters, we constructed a Dd-ras promoter deletion. Fusion of the promoter region of deletion 5' $\Delta 9$ (see Fig. 1) to the $\beta$-gluc gene results in expression of the gene fusion from only the middle and proximal promoters. As determined by RNA blots (Fig. 5C) and S1 nuclease analysis (data not shown), these transcripts from the middle and proximal promoter are expressed in multicellular aggregates. A very low level of $M$ transcript, but none from the $\mathrm{P}$ promoter, is seen in vegetative RNA, as is the case with the endogenous gene. No expression is observed from the now deleted distal promoter; however, a higher-molecular-weight, cryptic transcript is seen in vegetative cells due to initiation from a plasmid vector sequence (Fig. 5; R.K. Esch et al., in prep). A $5^{\prime} \Delta 9 /$ lac $Z$ construct was made and transformed into cells, and its temporal pattern of expression was examined. RNA blots (Fig. 5A) and S1 nuclease analysis (Fig. 6) indicate that the complete $D d$-ras/lacZ promoter exhibits a temporal pattern of expression indistinguishable from the endogenous transcripts (Fig. 5B). Moreover, the relative levels of the different transcripts seen in vegetative and developing cells are similar. Construct 5' $\Delta 9 /$ lac $Z$ shows expression only from the $M$ and P promoters during development. A very low level of expression in vegetative cells from the $M$ promoter is detected by $\mathrm{S} 1$ nuclease analysis. No $5^{\prime} \Delta 9 / 1$ acZ RNA from vegetative cells is seen on the RNA blot (see Fig. 5A). This construct, which uses a different vector background from that used for the $D d$-ras/ $\beta$-gluc construct, shows no expression from the cryptic vector promoter (see S1 nuclease analysis, Fig. 6). Vegetative cells transformed with this vector showed no $\beta$-gal staining (Fig. $4 \mathrm{~F})$ and had $\beta$-gal activity less than twofold over background and, more importantly, only $10 \%$ of the level seen in vegetative cells with the full-length promoter (Table 1). Therefore, we do not believe that the very low level of expression seen in Sl nuclease analysis is significant. During the multicellular stages, we observe a pattern generally similar to that seen with the parental construct at all stages, with a few important differences (Fig. 2, plate 2E,F). As seen in Figure 2, the relative level of staining of $5^{\prime} \Delta 9 / / a c Z$ transformants is reduced substantially in the posterior/basal cell zone relative to the tip at the first finger stage of $D d$-ras/lacZ. This was consistenly observed throughout 10 separate experiments, each yielding $>50$ multicellular structures and can be seen by comparing the staining pattern of first fingers in Figure 2, plate 1,D and F (first finger with complete promoter), which show posterior/basal disk staining to Figure 2, plate 2E, upper aggregate (first finger with $\Delta 9$ construct). (Note that the extent of basal staining in slugs and second fingers in cells expressing Dd-ras/lacZ depends on whether the basal cells have just been "sloughed off" as in Fig. 2, plates $1 \mathrm{H}$ and 2A.) The intensity of staining is severalfold lower than that observed with the complete promoter $(3 \mathrm{hr}$, instead of $20 \mathrm{~min}$, are required to obtain a similar staining intensity). This difference in expression between developing 5' $\triangle 9 / 1 a c Z$ and $D d$-ras/lac $Z$ transformants is also evident in $\beta$-gal assays as well as staining of dissociated aggregates and slugs (see Table 1; Fig. 4A-D). We note that 5' $\Delta 9 / 1 a c Z$ expression is not appreciably induced by cAMP in fastshake culture, an expected result given that only the $D$ promoter is greatly stimulated by cAMP. When these cells are allowed to develop, we observe $\beta$-gal levels con- 
sistent with those from vegetative cells plated directly for development, again showing a lower level of expression from 5' $\Delta 9 / 1 a c Z$ compared to $D d$-ras/lacZ (Table 1). We also observe stained cells scattered within the prespore zone of the early culminant that could be anteriorlike cells [cells within the prespore zone with some properties similar to prestalk cells (Sternfeld and David 1982; Devine and Loomis 1985)]. Finally, we note that not all the putative prestalk A cells in the anterior region are stained, suggesting that the cells expressing the $\sim 1.0 \mathrm{~kb}$ promoters may be a subset of the cells expressing the combined Dd-ras promoters. Although the relative number of $\beta$-gal-positive, putative anterior-like cells in the prespore zone appears to be higher in these transformants, we note that the time necessary for staining is much longer than that used to stain transformants carrying the complete promoter. In fact, staining of these cells is observed when the parental transfor- mants are overstained (data not shown). The putative anterior-like staining cells appear to represent a very small fraction of the total cells within the prespore zone. With the 5' $\Delta 9 /$ lac $Z$ transformants, we see the same general staining pattern in the early aggregate as was observed in the complete $D d$-ras promoter/lac $Z$ transformants, again indicating that vegetative expression does not play a direct role in the localization of $\beta$-gal-expressing cells during development.

\section{Directed cell movement}

As shown above, $\beta$-gal-staining cells initially are scattered throughout the developing aggregate and then, within $\sim 2 \mathrm{hr}$, become localized at the tip. Figure 2 , plate $1 \mathrm{~B}$, shows the staining pattern as the tip is beginning to form. As can be seen, there appears to be a spiral "procession" of cells from the basal/central regions of the

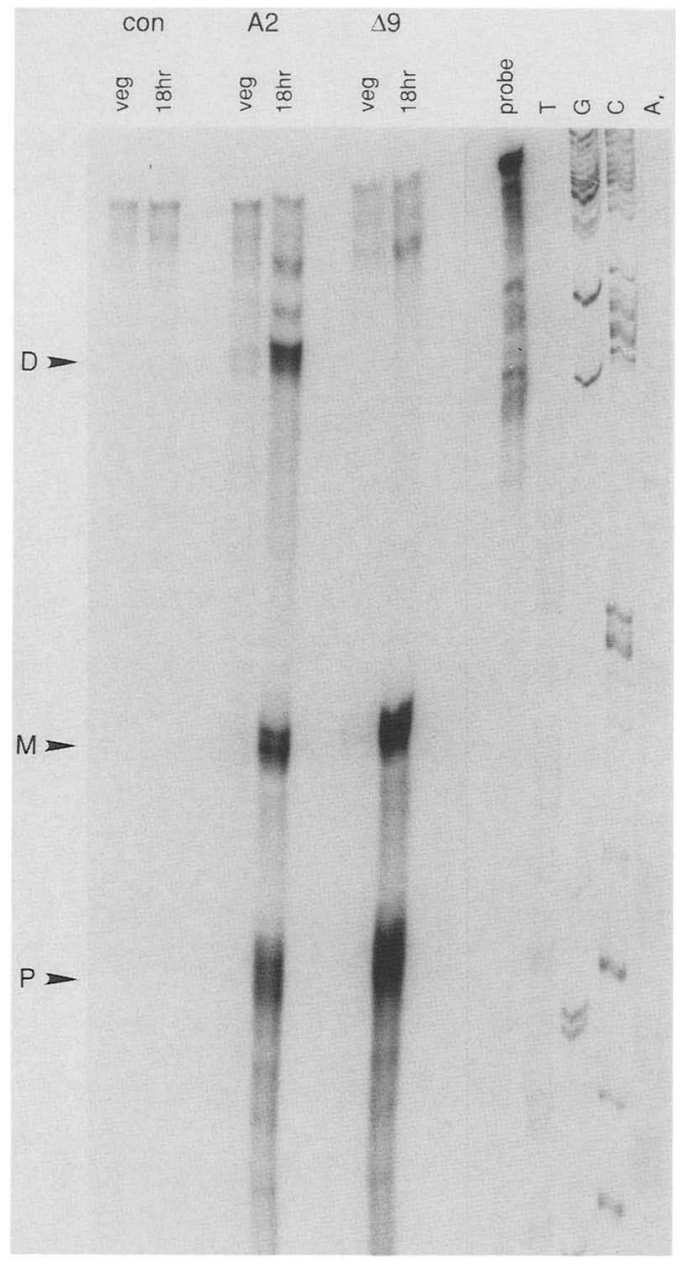

$\mathrm{S}_{1}$ Nuclease mapping construct

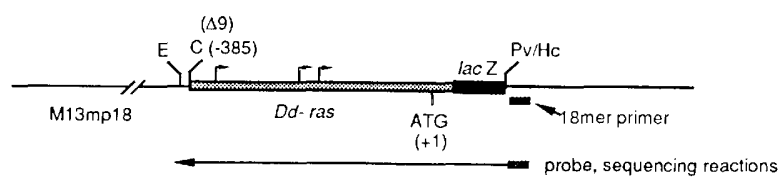

Figure 6. Dd-ras/lacZ DNA S1 nuclease protection. RNA was isolated from the indicated cell populations at the indicated times in development. RNA samples were hybridized with a single-stranded DNA probe as described in Materials and methods. The samples were then treated with S1 nuclease and size-fractionated on a denaturing polyacrylamide gel. Untreated probe and probe sequencing reactions are included for size reference. Labeled arrowheads show the start position of the distal $(D)$, middle $(M)$, and proximal $(P)$ promoters. Lowlevel expression from the distal promoter is evidence in RNA isolated from vegetative cells transformed with the $\mathrm{A} 2$ construct. Little if any protection by RNA from distal promoter is observed in the $\Delta 9$ lanes. The con lanes contain RNA from untransformed cells. We note that the intensity of the three protected fragments is not the same as observed in RNA blots of $D d$-ras/ $\beta$-gluc (Fig. 5, upper panel) or of the endogenous transcripts (see Reymond et al. 1984, 1985). In the S1 nuclease analysis, the large transcript gives a less intense band than expected. It is important to note that the untranslated region, which represents most of the protected fragments, is $>90 \% \mathrm{~A}+\mathrm{T}$. These long, very AT-rich sequences ( 360 nucleotides of 5 '-untranslated sequences for the distal promoter transcripts/ have a low sequence specificity and may also hybridize with other AT-rich sequences, resulting in nonspecific removal of the probe. The region of the probe that is complementary to the $l a c Z$ gene is more GC-rich and stabilizes the hybrid. However, the longer the AT-rich region of the probe is, the more destabilizing is its effect and the less efficient is hybridization over the entire protected region $1 \sim 360$ nucleotides for the distal promoter transcripts, $\sim 220$ nucleotides for the middle promoter transcripts, and $\sim 175$ for the proximal promoter transcripts). (For experimental details and a further analysis of the $5^{\prime}$ mapping of $D d$-ras gene transcripts, see Materials and methods.) 
aggregate toward the differentiating tip. The apparent ordered localization of $D d$-ras/lacZ-expressing cells to the tip and the commensurate loss of staining cells from the central regions suggest that movement of the $\beta$-galstaining cells to the tip within the context of the multicellular aggregate is directed (see Discussion). Although the total number of $\beta$-gal-expressing cells does not increase detectably over this time, we cannot eliminate the possibility that additional $D d$-ras/lacZ-expressing cells are induced during tip formation. Although we have observed that $\beta$-gal activity can be slowly lost from cells, the formation of the tip is very rapid, taking $<2 \mathrm{hr}$.

\section{Discussion}

Previous results suggest that this cell-type-specific $D d$ ras plays an essential role in both the signaling processes regulating chemotaxis in response to cAMP and during morphogenesis (Reymond et al. 1986; van Haastert et al. 1987). We have analyzed the pattern of Dd-ras/lacZ-expressing cells throughout development, and we believe that it reflects the localization of the Dd-ras endogenous gene product. We show that Dd-ras is expressed in a subpopulation of cells apparently randomly scattered in the early aggregate. Approximately $2 \mathrm{hr}$ later in development, Dd-ras expression is highly concentrated at the tip of the aggregate. Our staining data suggest that the localization of $D d$-ras/lacZ-expressing cells results from their sorting to the tip rather than from a rapid loss of $\beta$-gal in some cells and a rapid accumulation of $\beta$-gal in others and support similar conclusions of Williams et al. (1989) on the basis of examination of $D d 63$ expression. If $D d$-ras expression were induced in the developing tip de novo, we would expect to observe weakly staining cells in this region at the onset of tip formation, with the staining intensifying as tip formation proceeds. This is not observed. Although our data suggest that cells do not loss $\beta$-gal activity in aggregates and then induce new $\beta$-gal expression in tip cells, this cannot be excluded. The observed spiral pattern of $\beta$-gal-staining cells seen at the time of tip formation suggests that these cells may be moving toward the tip in response to a morphogenetic signal such as cAMP. This interpretation is consistent with the observations of Clark and Steck (1979), who postulated the presence of spiral patterning of cAMP oscillations within the aggregate, and with the demonstration of Tomchik and Devreotes (1981) that cAMP oscillations during aggregation are in the form of outward-moving spiral waves. Results from Coukell's laboratory have shown that isolated prestalk cells have a higher rate of chemotaxis toward cAMP than prespore cells do (Mee et al. 1986). A higher chemotactic rate of prestalk cells expressing $D d$-ras toward the tip-the apparent site of the initiation of the cAMP oscillationswould result in the eventual sorting of these cells to the tip. An involvement of cell sorting in cell-type patterning was proposed by Takeuchi and co-workers ( Tasaka and Takeuchi 1981; Tasaka et al. 1983).

Studies have suggested that the tip acts as an organizing region of the multicellular aggregate (see Durston
1976), which emits a cAMP pulse that propagates downward. Disruption of this oscillator by the addition of exogenous CAMP or phosphodiesterase or by dissection of the tip from the aggregate inhibits further differentiation (Raper 1940; Nestle and Sussman 1972). Our previous results indicate that the expression of an activated $D d$ ras $\left(\mathrm{Gly}_{12} \rightarrow \mathrm{Thr}_{12}\right)$ affects the cAMP signal transduction pathway controlling chemotaxis and results in the formation of aggregates with multiple tips (Reymond et al. 1986; van Haastert et al. 1987). As described above, our data and that of Williams et al. (1989) suggest that cell sorting is involved in tip formation, establishment of spatial patterning, and localization of $D d$-ras-expressing cells. The localized expression combined with the role of ras in Dictyostelium signal transduction suggests that ras may play a central role in cell migration necessary for the differentiation of the prestalk zone and in tip formation. Unexpectedly, the localized pattern of Dd-ras expression, which is induced by cAMP and not by DIF, is very similar, in both the aggregate and slug, to that of the prestalk A population expressing the DIF-induced gene Dd63 (Williams et al. 1989). From the available data, it appears that the same prestalk A cell population expresses both proteins. Our results also suggest that $D d$-ras, like $D d 63$, is expressed at a substantially lower level in prestalk B cells. Our observation that Dd-ras is prestalk specific is in disagreement with the suggestion by Williams and co-workers (Jermyn et al. 1987) that $D d$-ras is also expressed in prespore cells. The expression of $D d$-ras in the anterior, prestalk zone is similar to the pattern seen with the cAMP-inducible prestalk gene pst-cath (CP2) (Datta et al. 1986; Gomer et al. 1986).

Dd63 expression, like that of $D d$-ras, is first seen in an "apparently random" set of cells scattered through the aggregate. The results of Williams and co-workers (Jermyn et al. 1987; Williams et al. 1989), when compared to our results, indicate that the initial expression of Dd63 occurs after the cAMP-induced expression of $D d$-ras, which can first be detected at lightly staining cells in the very early aggregate. This is also consistent with the timing of accumulation of Dd-ras RNA (Reymond et al. 1984; Jermyn et al. 1987). Since $D d$-ras- and Dd63-expressing cells both appear to sort to the tip, our data suggest that the cells expressing $D d 63$ in response to DIF are probably the same cells that are already expressing Dd-ras in response to cAMP. Weeks and collaborators (Kwong et al. 1988a) have shown that there are two prestalk populations. One requires cAMP and DIF to induce stalk differentiation and a second requires only DIF. The cells requiring DIF and cAMP comprise the prestalk A population. It is possible that induction of some cAMP-induced prestalk genes may be required for Dd63 expression. This interpretation is supported by earlier data indicating that cAMP is required by starved cells to allow them to become competent to respond to DIF (Sobolewski et al. 1983; Berks and Kay 1988; Kwong et al. $1988 \mathrm{~b}$ ).

An unexpected property of Dd-ras cell patterning is the apparent initial random distribution of $D d$-ras-positive cells within the forming aggregate, which represent 
$\sim 15 \%$ of the total cells. Many of these interspersed with prespore cells in the developing presumptive prespore region (see Williams et al. 1989; Haberstroh and Firtel 1990) even though both $D d$-ras and prespore genes are induced by the same signal, cAMP. This strongly suggests that these cells may have inherent differences before they enter the aggregate. Earlier work from a number of laboratories has suggested that cells may be predisposed to become prestalk or prespore cells, depending on where the cells were in the cell cycle at the time of starvation (cells early in the cell cycle became prestalk cells while late cells became prespore cells) (Weijer et al. 1984; McDonald and Durston 1984; van Lookeren Campagne et al. 1984; McDonald 1986; Gomer and Firtel 1987; Wang et al. 1988b). Thus, it is possible that the cell cycle controls the initial, apparently random patterning of Dd-ras- and Dd63-expressing cells. Although all cells within the developing aggregate during aggregation receive the cAMP signal, they may respond differently due to differences in the cAMP-signaling pathways in the two cell types (see Spek et al. 1988; Ginsberg and Kimmel 1989|. These cells may then sort, possibly in response to cAMP signals, with the $D d$ ras-expressing prestalk cells migrating toward the tip. While positional information may not be essential in this initial patterning of prestalk A cells, it presumably is important in maintaining the pattern and in controlling Dd-ras and Dd63 expression later in development (this report; Schaap 1986; Wang et al. 1986, 1988a; Williams et al. 1987, 1989). The stabilization and maintenance of this pattern would require the interplay of cAMP, DIF, adenosine, $\mathrm{NH}_{4}^{+}$, and possibly other morphogens (Nestle and Sussman 1972; Williams et al. 1984; Schaap 1986; Schaap and Wang 1986; Spek et al. 1988; Wang et al. 1988). It is possible that the cell sorting mechanism combined with the preferential expression of appropriate gene products initially establishes gradients that may be required to stabilize the spatial pattern established in the tipped aggregate.

\section{Materials and methods}

\section{General methods}

Axenically grown KAx-3 cells were used in these studies (Mehdy et al. 1983). Vegetative Dictyostelium cells were transformed by electroporation and stable transformants selected at G418 concentration of 10 or $15 \mu \mathrm{g} / \mathrm{ml}$ as described previously (Howard et al. 1988; Dynes and Firtel 1989). Whole transformed populations were utilized for most analyses, except as indicated. Transformed populations were maintained as logarithmically dividing cells.

Clonal isolates were obtained by plating cells in association with Klebsiella aerogenes on $\mathrm{SM}^{+} / 3$ agar petri dishes (for details, see Firtel and Chapman 1990).

\section{Cytological staining and $\beta$-gal assays}

Cells were plated for development on white Millipore filters (HAWP) and placed on $12 \mathrm{~mm}$ phosphate buffer $(\mathrm{pH}$ 6.1) agar plates. At appropriate developmental times, filters were fixed and stained for $\beta$-gal activity as described previously (Dinger- mann et al. 1989; Williams et al. 1989; Haberstroh and Firtel $1990)$.

The expression in vegetative or single, dissociated developing cells was examined by first fixing the cells on microscopic slides prior to histochemical staining as described above. $\beta$-Gal was assayed in freeze-thawed whole cell lysates in $10 \mathrm{~mm}$ Tris (pH 8.0) and $5 \mathrm{~mm}$ p-nitrophenyl $\beta$-D-galactopyranoside. The reactions were stopped with an equal volume of $0.5 \mathrm{M} \mathrm{Na}_{2} \mathrm{CO}_{3}$ and the amount of $p$-nitrophenol quantitated by measuring the absorption at $A_{420}$. Activity is presented as pmoles $/ \mathrm{min} \cdot \mu \mathrm{g}$ protein. Total protein content was assayed using the Bio-Rad reagent.

\section{Expression of Dd-ras/lacZ fusions in fast-shaking culture}

Logarithmically growing cells were harvested by centrifugation, washed twice with cold MES-PDF (non-nutrient-buffered salt solution), and resusupended in MES-PDF at $5 \times 10^{6}$ cells/ $\mathrm{ml}$ (Mehdy and Firtel 1985; Mann and Firtel 1987). The cells were then distributed evenly into pairs of flasks and allowed to shake at $240 \mathrm{rpm}$ for $6 \mathrm{hr}$. EDTA (pH 7.2) was then added to each shaking culture to a concentration of $2 \mathrm{mM}$. cAMP (to 300 $\mu \mathrm{M}$ ) was added to one flask of each pair after $6 \mathrm{hr}, 8 \mathrm{hr}$, and $10 \mathrm{hr}$ of shaking. All cells were then harvested after $12 \mathrm{hr}$ of shaking.

\section{Vector constructs}

$\beta$-Gal expression vectors are based on SP60/lacZ as described by Haberstroh and Firtel (1990). For the combined and proximal promoter constructs, the $D d$-ras $5^{\prime}$-flanking region, $5^{\prime}$-untranslated region, and 11 codons of $D d$-ras-coding sequence were fused in-frame to the E. coli lacZ construct from vector SP60/ lacZ (see Fig. 1). For the middle and proximal promoter construct, $5^{\prime}$ deletion $5^{\prime} \Delta 9$ (see Fig. 1) was used. This was fused to the SpeI site in the $5^{\prime}$-untranslated region of $S P 60 / \beta$-gal construct. For details of the $l a c Z$ expression vector, see Haberstroh and Firtel (1990).

The $D d$-ras/ $\beta$-gluc gene fusion contained a 520 -bp fragment of the $E$. coli gene encoding $\beta$-gluc fused to $680 \mathrm{bp}$ of $5^{\prime}$-upstream and untranslated sequences and $35 \mathrm{bp}$ of the coding region of $D d$-ras. This was followed by a 360 -bp fragment carrying the transcription termination/polyadenylation sequences from Act8 (see also Datta and Firtel 1987). For selection of stable transformants in Dictyostelium, the vector also contained the Act6-G418 gene fusion (see Haberstroh and Firtel 1990). These fragments were cloned into the $E$. coli vector pUC19.

\section{S1 nuclease analysis}

An 18-mer oligonucleotide primer complementary to the M13 polylinker region was synthesized. This primer was annealed to single-stranded M13 phage DNA containing 80 bp of lacZ coding sequence fused to $442 \mathrm{bp}$ of $5^{\prime} \mathrm{Dd}$-ras sequence (Fig. 5). $\left[\alpha-{ }^{-32} \mathrm{P}\right] \mathrm{dCTP}$ continuously labeled single-stranded DNA probes were then generated by DNA polymerase I Klenow fragmentcatalyzed elongation of the primer. The elongation products were then digested with EcoRI, which yields linearized M13 vector and releases probe fragments. The samples are then denatured and size-fractionated on polyacrylamide urea gels, and full-length probe fragments were isolated. Total RNA was isolated from reporter gene transformants vegetatively growing and at various times in development. The RNA samples were then hybridized with full-length probe at $42^{\circ} \mathrm{C}$ for $18 \mathrm{hr}$. Icecold digestion buffer containing S1 nuclease was then added to 
a final concentration of $400 \mathrm{U} / \mathrm{ml}$ of the nuclease, and the samples were immediately transferred to $20^{\circ} \mathrm{C}$ and incubated for $45 \mathrm{~min}$. The digestion products were then size-fractionated by polyacylamide gel electrophoresis and visualized by autoradiography (Beck and Sharp 1977).

We used several approaches to minimize differential stability of the three hybrid species (see legend to Fig. 5). Increasing the concentration of probe had no effect on band intensity and resulted in substantially higher background. Increasing the S1 nuclease concentration or the reaction temperature caused internal "nicking" of the hybrids. In addition, these long AT-rich regions tend to be more sensitive to internal nicking, thus decreasing the yield of protected bands from longer transcripts. Primer extension analysis was unsuccessful due to early termination within the AT-rich regions.

\section{Acknowledgments}

We thank L. Haberstroh for providing constructs and for helpful discussions and Jeff Williams and Rob Kay for communicating results prior to publication. We thank J. Roth for assistance in preparing this manuscript. R.K.E. is a National Institutes of Health Predoctoral Trainee, supported for part of this work by grant U.S. Public Health Service GM37830. The research was supported by U.S.Public Health Service grants to R.A.F.

The publication costs of this article were defrayed in part by payment of page charges. This article must therefore be hereby marked "advertisement" in accordance with 18 USC section 1734 solely to indicate this fact.

\section{References}

Barklis, E. and H.F. Lodish. 1983. Regulation of Dictyostelium discoideum mRNAs specific for prespore and prestalk cells. Cell 32: 1139-1148.

Berk, A.J. and P.A. Sharp. 1977. Sizing and mapping of early adenovirus mRNAs by gel electrophoresis of S1 endonuclease digested hybrids. Cell 12: 721-732.

Berks, M. and R.R. Kay. 1988. Cyclic AMP is an inhibitor of stalk cells differentiation in Dictyostelium discoideum. Dev. Biol. 126: 108-114.

Clark, R.L. and T.L. Steck. 1979. Morphogenesis in Dictyostelium: An orbital hypothesis. Science 204: 1163-1167.

Datta, S. and R.A. Firtel. 1987. Identification of the sequences controlling cyclic AMP regulation and cell-type specific expression of a prestalk-specific gene in Dictyostelium discoideum. Mol. Cell. Biol. 7: 149-159.

Datta, S., R.H. Gomer, and R.A. Firtel. 1986. Spatial and temporal regulation of a foreign gene by a prestalk-specific promoter in transformed Dictyostelium discoideum. Mol. Cell. Biol. 6: 811-820.

Devine, K. and W. Loomis. 1985. Molecular characterization of anterior-like cells in Dictyostelium discoideum. Dev. Biol. 107: 364-372.

Devreotes, P. 1989. Dictyostelium discoideum: A model system for cell-cell interactions in development. Science 245: 1054-1058.

Dingermann, T., N. Reindl, I. Werner, M. Hildebrandt, W. Nellen, A. Harwood, J.G. Williams, and K. Nerke. 1989. Optimization and in situ detection of Escherichia coli $\beta$-galactosidase gene expression in Dictyostelium discoideum. Gene 85: 353-362.

Durston, A.J. 1976. Tip formation is regulated by an inhibitor gradient in the Dictyostelium discoideum slug. Nature 263: $126-129$.
Dynes, J.L. and R.A. Firtel. 1989. Molecular complementation of a genetic marker in Dictyostelium using a genomic DNA library. Proc. Natl. Acad. Sci. 86: 7966-7970.

Firtel, R.A., P.J.M. van Haastert, A.R. Kimmel, and P. Devreotes. 1989. G-protein linked signal transduction pathways in development: Dictyostelium as an experimental system. Cell 58: 235-239.

Ginsburg, G. and A.R. Kimmel. 1989. Inositol triphosphate and diaglycerol can differentially modulate gene expression in Dictyostelium. Proc. Natl. Acad. Sci. 86:9332-9336.

Gomer, R.H. and R.A. Firtel. 1987. Cell-autonomous determination of cell-type choice in Dictyostelium development by cell-cycle phase. Science 237: 758-762.

Gomer, R.H., S. Datta, and R.A. Firtel. 1986. Cellular and subcellular distribution of a cAMP-regulated prestalk protein and prespore protein in Dictyostelium discoideum: A study on the ontogeny of prestalk and prespore cells. J. Cell Biol. 103: 1999-2015.

Haberstroh, L. and R.A. Firtel. 1990. A spatial gradient expression of a cAMP-regulated prespore cell-type-specific gene in Dictyostelium. Genes Dev. 4: 596-612.

Howard, P.K., K.G. Ahern, and R.A. Firtel. 1988. Establishment of a transient expression system for Dictyostelium discoideum. Nucleic Acids Res. 16: 2613-2623.

Jermyn, K.A., M. Berks, R.R. Kay, and J.G. Williams. 1987. Two distinct classes of prestalk-enriched mRNA sequences in Dictyostelium discoideum. Development 100: 745-755.

Jermyn, K.A., K.T.I. Duffy, and J.G. Williams. 1989. A new anatomy of the prestalk zone in Dictyostelium. Nature 340: $144-146$.

Krefft, M., L. Voet, J.H. Gregg, H. Mairhofer, and K.L. Williams. 1984. Evidence that positional information is used to establish the prestalk-prespore pattern in Dictyostelium discoideum aggregates. EMBO I. 3: 201-206.

Kwong, L., A. Sobolewski, L. Atkinson, and G. Weeks. 1988a. Stalk cell formation in monolayers from isolated prestalk and prespore cells of Dictyostelium discoideum: Evidence for two populations of prestalk cells. Development 104: $121-127$.

Kwong, L., A. Sobolewski, and G. Weeks. 1988b. The effect of cyclic AMP on the DIF mediated formation of stalk cells in low density monolayers of Dictyostelium discoideum. Differentiation 37: 1-6.

Loomis, W.F., ed. 1982. The development of Dictyostelium discoideum. Academic Press, New York.

McDonald, S.A. 1986. Cell-cycle regulation of center initiation in Dictostelium discoideum. Dev. Biol. 117: 546-549.

McDonald S.A. and A.J. Durston. 1984. The cell cycle and sorting behaviour in Dictyostelium discoideum. J. Cell Sci. 66: 195-204.

Mann, S.K.O. and R.A. Firtel. 1987. Cyclic AMP regulation of early gene expression in Dictyostelium discoideum: Mediation via the cell surface cyclic AMP receptor. Mol. Cell. Biol. 7: 458-469.

Mee, J.D., C. Tortolo, and M.B. Coukell. 1986. Chemotaxis associated properties of separated prestalk and prespore cells. Biochem. Cell Biol. 64: 722-732.

Mehdy, M.C. and R.A. Firtel. 1985. A secreted factor and cAMP jointly regulate cell-type-specific gene expression in Dictyostelium. Mol. Cell. Biol. 5: 705-713.

Mehdy, M.C., D. Ratner, and R.A. Firtel. 1983. Induction and modulation of cell-type-specific gene expression in Dictyostelium. Cell 32: 761-771.

Nestle, M. and M. Sussman. 1972. The effect of cyclic AMP on morphogenesis and enzyme accumulation in Dictyostelium discoideum. Dev. Biol. 28: 545-554. 
Pawson, T., T. Amiel, E. Hinza, N. Auersperg, N. Neave, A. Sobolewski, and G. Weeks. 1985. Regulation of a ras-related protein during development of Dictyostelium discoideum. Mol. Cell. Biol. 5: 33-39.

Raper, K.B. 1940. Pseudoplasmodium formation and organization in Dictyostelium discoideum. I. Elisha Mitchell Sci. Soc. 56: $241-282$.

Reymond, C.D., R.H. Gomer, M.C. Mehdy, and R.A. Firtel. 1984. Developmental regulation of a Dictyostelium gene encoding a protein homologous to mammalian ras protein. Cell 39: 141-148.

Reymond, C.D., W. Nellen, and R.A. Firtel. 1985. Regulated expression of ras gene constructs in Dictyostelium transformants. Proc. Natl. Acad. Sci. 82: 7005-7009.

Reymond, C.D., R.H. Gomer, W. Nellen, A. Theibert, P. Devreotes, and R.A. Firtel. 1986. Phenotypic changes induced by a mutated ras gene during development of Dictyostelium transformants. Nature 323: 340-343.

Robbins, S.M., J.G. Weeks, K.A. Jermyn, G.B. Spiegelman, and G. Weeks. 1989. Growing and developing Dictyostelium cells express different ras genes. Proc. Natl. Acad. Sci. 86: $938-942$.

Rutherford, C.L. and S.S. Brown. 1983. Cell type specific inhibition of cAMP phosphodiesterase activity during terminal differentiation in Dictyostelium discoideum. Dev. Biol. 96: 296-303.

Schaap, P. 1986. Regulation of size and pattern in the cellular slime molds. Differentiationa 33: 1-16.

Schaap, P. and M. Wang. 1986. Interactions between adenosine and oscillatory cAMP signaling. Cell 45: 137-144.

Sobolewski, A., N. Neave, and G. Weeks. 1983. The induction of stalk differentiation in submerged monolayers of Dictyostelium discoideum: Characterization of the temporal sequence for the molecular requirements. Differentiation 25: $93-100$.

Spek, W., K. van Drunen, R. van Eijk, and P. Schaap. 1988. Opposite effects of adenosine on two types of cAMP-induced gene expression in Dictyostelium indicate the involvement of at least two different intracellular pathways for the transduction of cAMP signals. FEBS Lett. 228: 231-234.

Sternfeld, J. and C.N. David. 1982. Fate and regulation of anterior-like cells in Dictyostelium slugs. Dev. Biol. 93: 111118.

Tasaka, M. and I. Takeuchi. 1981. Role of cell sorting in pattern formation in Dictyostelium discoideum. Differentiation 18: $191-196$.

Tasaka, M., T. Noce, and I. Takeuchi. 1983. Prestalk and prespore differentiation in Dictyostelium as detected by cell type-specific monoclonal antibodies. Proc. Natl. Acad. Sci. 80: $5340-5344$.

Tomchik, K. and P.N. Devreotes. 1981. Cyclic AMP waves in Dictyostelium discoideum: A demonstration by isotope detection fluorography. Science 212: 443-446.

van Haastert, P.J.M., F. Kesbeke, C.D. Reymond, R.A. Firtel, E. Luderus, and R. van Driel. 1987. Aberrant transmembrane signal transduction in Dictyostelium cells expressing a mutated ras gene. Proc. Natl. Acad. Sci. 84: 4905-4909.

van Lookeren Campagne, M.M., G. Duschl, and N.C. David. 1984. Dependence of cell type proportioning and sorting on cell cycle phase in Dictyostelium discoideum. I. Cell Sci. 70: $133-145$.

Wang, M., P.J.M. van Haastert, and P. Schaap. 1986. Multiple effects of differentiation-inducing factor on prespore differentiation and cyclic-AMP signal transduction in Dictyostelium. Differentiation 33: 24-28.

Wang, M., R.J. Aerts, W. Spek, and P. Schaap. 1988a. Cell cycle phase in Dictyostelium discoideum is correlated with the expression of cyclic AMP production, detection, and degradation. Dev. Biol. 125: 410-416.

Wang, M., R. van Driel, and P. Schaap. 1988b. Cyclic AMPphosphodiesterase induces dedifferentiation of prespore cells in Dictyostelium discoideum slugs: Evidence that cyclic AMP is the morphogenetic signal for prespore differentiation. Development 103: 611-618.

Weijer, C.J., G. Duschl, and C.N. David. 1984. Dependence of cell-type proportioning and sorting on cell cycle phase in Dictyostelium discoideum. J. Cell Sci. 70: 133-145.

Williams, J.G., E.M. Elder, and M. Sussman. 1984. Modulation of the cAMP relay in Dictyostelium discoideum by ammonia and other metabolites: Possible morphogenetic consequences. Dev. Biol. 105: 377-388.

Williams, J.G., M.J. North, and H. Mahbubani. 1985. A developmentally regulated cysteine proteinase in Dictyostelium discoideum. EMBO /. 4: 999-1006.

Williams, J.G., A. Ceccarelli, S. McRobbie, H. Mahbubani, R.R. Kay, A. Early, M. Berks, and K.A. Jermyn. 1987. Direct induction of Dictyostelium prestalk gene expression by DIF provides evidence that DIF is a morphogen. Cell 49: 185192.

Williams, J.G., K.T. Duffy, D.P. Lane, S.J. McRobbie, A.J. Harwood, D. Traynor, R.R. Kay, and K.A. Jermyn. 1989. Origins of the prestalk-prespore pattern in Dictyostelium development. Cell 59: 1157-1163. 


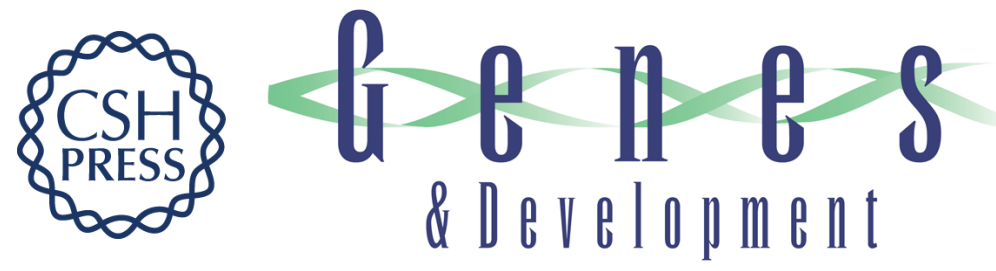

\section{cAMP and cell sorting control the spatial expression of a developmentally essential cell-type-specific ras gene in Dictyostelium.}

R K Esch and R A Firtel

Genes Dev. 1991, 5:

Access the most recent version at doi:10.1101/gad.5.1.9

References This article cites 54 articles, 23 of which can be accessed free at: http://genesdev.cshlp.org/content/5/1/9.full.html\#ref-list-1

License

Email Alerting Service

Receive free email alerts when new articles cite this article - sign up in the box at the top right corner of the article or click here.

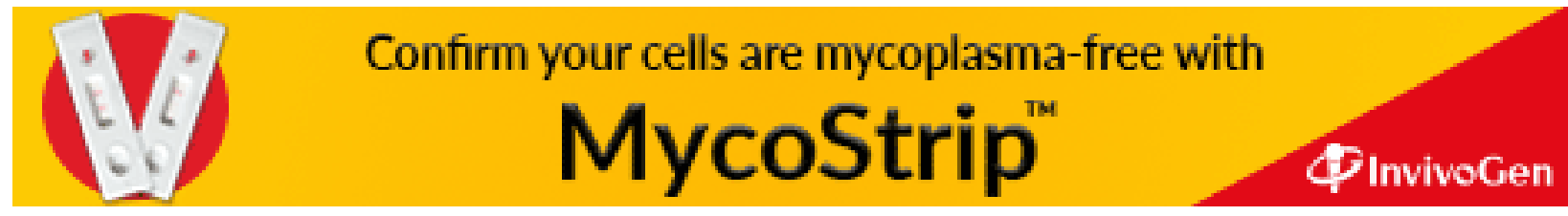

